\title{
Formulation and Evaluation of Herbal Hair Gel for Hair Growth Potential
}

\author{
T Regupathi ${ }^{1 *}$, K Chitra ${ }^{2}$, K Ruckmani ${ }^{3}$, KG Lalitha4 and Mohan Kumar ${ }^{3}$ \\ ${ }^{1}$ Department of Pharmaceutics, Ultra College of Pharmacy, India \\ ${ }^{2}$ Department of Pharmaceutical Chemistry, Sri Ramachandra University, India \\ ${ }^{3}$ Department of Pharmaceutical Technology, BIT Campus Anna University, India \\ ${ }^{4}$ Department of Pharmaceutical Chemistry, Ultra College of Pharmacy, India
}

Submission: January 07, 2017; Published: February 22, 2017

*Corresponding author: T Regupathi, Ultra College of Pharmacy, 4/235, College Road, Thasildar Nagar, Madurai-625 020, Tamil Nadu, India, Tel: 09443432476; Email: poornareg@yahoo.co.in

\begin{abstract}
Ethyl acetate soluble fraction of ethanolic extract of Eclipta alba and Lippia nodiflora was evaluated for its potential on hair growth by in vivo method. In vivo, $5 \%$ and $10 \%$ extract of E. alba and L. nodiflora alone and also in combination of $5 \%$ of E. alba and $5 \%$ of $L$. nodiflora in gel formulation was applied topically over the shaved skin of black mice and monitored and assessed for 30 days. The length of hair and the different cyclic phases of hair follicles like anagen and telogen phases were determined at different time periods. From the study, topical use of gel formulations containing extracts of E. alba and L. nodiflora alone and also in combination onto the shaved area on the animals, produced a significant increase in the rate of hair growth compared with negative control (simple gel alone). It is concluded that the ethyl acetate soluble fraction of ethanolic extract of E. alba (5\%) and L. nodiflora (5\%) combination gel formulation exhibits more potency on hair growth activity.

Keywords: Eclipta alba, Lippia nodiflora, Carbopol 934, Hair growth initiation, Hair growth completion, Histopathology, Hair follicles

Abbreviations: PEG: Poly Ethylene Glycol; EEEA: Extract of Eclipta alba L., Hassk; EELN: Extract of Lippia nodiflora; PDII: Primary Dermal Irritation Index; VEGF: Vascular Endothelial Growth Factors; KGF: Keratinocyte Growth Factors; HGF: Hepatocyte Growth Factors; EGCG: Epigallocatechin-3-gallate
\end{abstract}

\section{Introduction}

Recently, the number of men and women who suffered from hair loss and/or hair thinning is increasing in worldwide. Hair loss is a dermatological disorder, and the surge for discovering natural products with hair growth promoting potential is continuous [1,2]. Hair loss or alopecia is a common patient complaint and a source of significant psychological and physical distress [3]. Many factors such as metabolism, hormones, heredity and side effects of antineoplastic and immunosuppressant drugs, have been negatively affecting the healthy growth of hair. According to one survey, androgenic alopecia on its own eventually affects approximately $50 \%$ of the world's adult population $[4,5]$. In androgenic alopecia it is assumed that the genetically predisposed hair follicles are the target for androgen - stimulated hair follicle miniaturization, leading to gradual replacement of large, pigmented hairs (terminal hairs) by barely visible, depigmented hairs (vellus hairs) in affected areas [4]. It is dyhydrotestosterone medicated process, characterized by continuous miniaturization of androgen reactive hair follicles and accompanied by per follicular fibrosis of follicular units in histological examination [6].

Androgenic alopecia results in a decrease in hair follicle size accompanied by a decrease in the duration of anagen; anagen is the active phase of the hair in which hair is living and growing and an increase in the percentage hair follicles in telogen; telogen is the resting phase and accounts for $10-15 \%$ of all hairs [7]. Androgens are considered to be one of the most important causes for alopecia apart from a variety of other factors [8]. Thus it is very important to develop new therapeutic materials to stop hair loss and to enhance hair growth. Alternative medicine is one interesting area, which is getting more popular. Although it has not yet been incorporated into the mainstream of medical care because of limited scientific evidences and lack of mechanistic understanding, alternative medicine is becoming an increasingly attractive approach all over the world [9]. Natural products in the form of herbal formulations are available on the market and are used as hair tonic, hair growth promoter, hair conditioner, 
hair-cleansing agent, antidandruff agents, as well as for the treatment of alopecia and lice infection [10].

A number of herbal products have been acclaimed with hair growth promoting activity [11]. The traditional system of medicine in India acclaims a number of herbal drugs for hair growth promotion [12] but lack of sound scientific backing and knowledge limits their usage. Eclipta alba L. Hassk. is an annual herbaceous plant, commonly known as king of hairs. Main active principles consist of coumestans like wedelolactone, desmethylwedelolactone, furanocoumarins, oleanane and taraxastane glycosides $[13,14]$. The plant is commonly used in hair oil all over India for healthy black and long hair [15]. It has been reported to show protective effect on experimental liver damage in rats and mice [16]. In Ayurveda, the root powder is used for treating hepatitis, enlarged spleen and skin disorders. Mixed with a little oil when applied to the head, the herb relieves headache.

Lippia nodiflora is the important member of the family verbenaceae showing a variety of medicinal uses. It can be the source of the indigenous medicine. In India, it is found in the warmer parts including Andhra Pradesh, Karnataka, Kerala, and Maharashtra, some parts of Rajasthan, Tamil Nadu, Uttar Pradesh and West Bengal. The plant contains a variety of constituents such as triterpenoids, flavonoids, phenols, steroids, and many others. Among these flavonoids were the most commonly found constituent. Nodifloretin (3), $\beta$-sitosterol glycoside and stigmasterol glycoside from the leaves of $L$. nodiflora). Nodifloridin A (1) and Nodifloridin B (2) along with lactose, maltose, glucose, fructose, and xylose were isolated from the plant [17]. The plant is used as gastro protective effect [18], anti inflammatory, antineoplastic [19], antioxidant [20] and diuretic [21]. The present study is an effort to formulate and evaluate hair growth promoting activity of various herbal hair gel formulations, which include various concentrations of Eclipta alba L. Hassk. and Lippia nodiflora Linn.

\section{Materials and Methods}

\section{Collection and authentication of plant materials}

The plant specimens for the proposed study Eclipta alba L., Hassk and Lippia nodiflora Linn., were collected from the paddy fields and other irrigated fields in and around Madurai District, Tamil Nadu, India during the month of October. The herbarium of these plants was identified and authenticated by Department of Botany, American college of Arts and Science, Madurai, Tamil Nadu. The plants were dried under shade.

\section{Preparation of plant extracts}

The fresh whole plant of E. alba and L. nodiflora was washed with distilled water to removed unwanted foreign materials like soil and dusts. After, washed plant material was dried under shade at room temperature without direct exposure of sunrays.
It was then coarsely grounded by using mechanical device. The powdered plant material was passed through sieve no 40 and stored in an airtight container for further use. The coarsely powdered plant materials of E. alba and L. nodiflora (2000 g) were extracted separately to exhaustion in a soxhlet apparatus for 72 hours by using petroleum ether $\left(60-80^{\circ} \mathrm{C}\right)$ and ethanol $(95$ $\%)$ solvent (Merk \& Spectrum Chemicals, India) systems. All the extracts were filtered through a cotton plug followed by what mann filter paper (No.1) and then concentrated by using a rotary evaporator at low temperature $\left(40-50^{\circ} \mathrm{C}\right)$ and reduced pressure to get $24.4 \mathrm{~g}$ and $108.6 \mathrm{~g}$ (E. alba) and $20.6 \mathrm{~g}$ and $100.2 \mathrm{~g}$ ( $L$. nodiflora) respectively. The extracts were preserved in airtight containers and kept at $4^{\circ} \mathrm{C}$ until further use. The ethanolic extract was further fractionated by ethyl acetate and this ethyl acetate soluble fraction was used for further studies.

\section{Preparation of formulation}

Five different herbal hair gel formulations were prepared by simple gel formulation preparation method with carbopol gel base. The gel formula contains methyl paraben sodium, glycerine, poly ethylene glycol (PEG), carbopol 934, PVP and triethanolamine. Carbopol 934 two grams and measured quantity of extracts was dispersed in $80 \mathrm{ml}$ of distilled water and mixed by stirring continuously in a magnetic stirrer at $800 \mathrm{rpm}$ for $1 \mathrm{~h}$. Glycerin $3 \mathrm{ml}$ was added to the mixture under continuous stirring. The mixture was neutralized by drop wise addition of $50 \%$ triethanolamine. Mixing was continued until a transparent gel was formed. The ethyl acetate soluble fraction of ethanolic extract of Eclipta alba L., Hassk (EEEA) and Lippia nodiflora (EELN) in various concentrations as shown in Table 1 were incorporated in the carbopol base gel and prepared herbal hair gel formulations.

Table 1: Formulae of herbal hair gel.

\begin{tabular}{|c|c|c|c|c|c|}
\hline Formulation & HG1 & HG2 & HG3 & HG4 & HG5 \\
\hline Herbal Extract (g) & $\begin{array}{c}5 \text { \% of } \\
\text { EEEA }\end{array}$ & $\begin{array}{c}10 \\
\% \text { of } \\
\text { EEEA }\end{array}$ & $\begin{array}{c}5 \% \text { of } \\
\text { EELN }\end{array}$ & $\begin{array}{c}10 \% \text { of } \\
\text { EELN }\end{array}$ & $\begin{array}{c}5 \% \text { of } \\
\text { EEEA + } \\
5 \% \text { of } \\
\text { EELN }\end{array}$ \\
\hline Carbopol 934 (g) & 2 & 2 & 2 & 2 & 2 \\
\hline PVP (mg) & 5 & 5 & 5 & 5 & 5 \\
\hline $\begin{array}{c}\text { Methyl paraben } \\
\text { sodium (mg) }\end{array}$ & 75 & 75 & 75 & 75 & 75 \\
\hline \begin{tabular}{c} 
Glycerine (ml) \\
\hline PEG (ml)
\end{tabular} & 3 & 3 & 3 & 3 & 3 \\
\hline $\begin{array}{c}\text { Triethanolamine } \\
\text { (ml) }\end{array}$ & 1.5 & 1.5 & 1.5 & 1.5 & 1.5 \\
\hline
\end{tabular}




\section{Animals}

Healthy C57 / BL6 mice 25 - 30 gms of either sex were purchased from NIN Hyderabad (India) and used for hair growth promoting activity. The experimental protocol was approved by the Institutional animal ethics committee, Ultra College of Pharmacy, Madurai Approval number UCP/IAEC/2014/091. Animals were placed in cages and kept in standard environmental conditions, fed with standard diet ad libitum and allowed free access to drinking water. They were acclimated 7 days before entry into subsequent study.

\section{Primary dermal irritation study}

Male New Zealand White Rabbits were used for dermal irritancy experiment. The experimental protocol was approved by the Institutional animal ethics committee, Approval No. IAEC / XXXVIII / SRU / 356 / 2014. OECD 404 guidelines were adhered during the maintenance and experiment. In dermal irritancy study EEEA (5 and $10 \%$ ) and EELN (5 and $10 \%$ ) gel formulation was used on rabbits. Approximately 24 hours before the test, fur was removed by closely clipping the dorsal area of the trunk of the animals. Half a gram of the herbal gel formulation was applied to a small area (approximately $6 \mathrm{~cm} 2$ ) of skin and covered with a gauze patch, which is held in place with non-irritating tape. All animals were examined for signs of erythema and oedema, and the responses scored at 60 minutes, and then at 24, 48 and 72 hours after patch removal [22] (Tables 2 \& 3).

Table 2: Grading of skin reactions.

\begin{tabular}{|c|c|}
\hline Grading of skin reactions & Erythema and Eschar Formation \\
\hline No erythema & 0 \\
\hline $\begin{array}{c}\text { Very slight erythema (barely } \\
\text { perceptible) }\end{array}$ & 2 \\
\hline Well defined erythema & 3 \\
\hline $\begin{array}{c}\text { Moderate to severe erythema } \\
\text { to eschar formation preventing } \\
\text { grading of erythema }\end{array}$ & 4 \\
\hline Maximum possible & 4 \\
\hline
\end{tabular}

Table 3: Oedema Formation.

\begin{tabular}{|c|c|}
\hline Oedema Formation & 0 \\
\hline No oedema & 1 \\
\hline Very slight oedema (barely perceptible) & 2 \\
\hline $\begin{array}{c}\text { Slight oedema (edges of area well } \\
\text { defined by definite raising) }\end{array}$ & 3 \\
\hline $\begin{array}{c}\text { Moderate oedema (raised } \\
\text { approximately 1 mm) }\end{array}$ & 4 \\
\hline $\begin{array}{c}\text { Severe oedema (raised more than 1 mm } \\
\text { and extending beyond area of exposure) }\end{array}$ & 4 \\
\hline Maximum possible & \\
\hline
\end{tabular}

PDII observed on $12+24+48+72$ hrs

Primary Dermal Irritation Index (PDII) =

5.6 Classification system based on PDII

$<0.5$ : non - irritating,

0.5 - 2.0: slightly irritating,

2.1 - 5.0: moderately irritating and

$>5.0$ : severely irritating.

\section{Treatment for hair growth activity in vivo [23]}

Forty two C57/BL6 mice were divided into seven groups of 6 animals in each group. Hairs from $3 \mathrm{~cm} 2$ area at the dorsal portion of all the mice were shaved using electric shavers and applied with marketed hair remover to completely remove hair. Group 1 served as a negative control was applied with simple gel where there was no drug treatment. Group 2 was topically applied with $2 \%$ minoxidil over the shaved area as positive control. Group 3 and 4 was topically applied with $5 \%$ and 10 $\% \mathrm{w} / \mathrm{w}$ gel formulation of EEEA respectively. Group 5 and 6 was applied with $5 \%$ and $10 \% \mathrm{w} / \mathrm{w}$ gel formulation of EELN respectively. Group 7 was applied with combination of EEEA (5 $\%$ ) and EELN (5 \%) gel formulation. All the gel and standard drug were applied once in a day. The treatment was continued for 30 days and hair growth pattern was observed and tabulated. Skin biopsies were taken on the $30^{\text {th }}$ day for follicular observation. Increase in thickness and presence of the follicles in the subcutis layer were taken as evidence for transition of follicles from telogen to anagen phase of hair growth.

\section{Qualitative hair growth study}

Qualitative hair growth analysis was undertaken by visual observation of two parameters: hair growth initiation time (i.e. minimum time to initiate hair growth on denuded skin region) and hair growth completion time (i.e. minimum time taken to complete cover the denuded skin region with new hair) [24,25].

\section{Quantitative hair growth study}

I. Hair length determination: Hair was plucked randomly using sterile forceps from the shaved dorsal area of mice on $10^{\text {th }}, 20^{\text {th }}$ and $30^{\text {th }}$ day of treatment. Hair length was measured and the results were recorded as mean length \pm SEM of 25 hairs [2].

II. Histological studies: One mouse from each group was authenticated after 30 days of treatment. Skin biopsies were obtained from the shaved portion and preserved in 10 $\%$ formalin. Sections of tissues were implanted in paraffin wax and sectioned into a thickness of $10 \mu \mathrm{m}$. The sectioned tissues were stained with haematoxylin and eosin and the follicular phases of hairs were examined under microscope 
with an ocular micrometer and also the number of hair follicles per mm area of skin, and percentage ratio of hair follicles in different cyclic phases, like anagen (growth phase) and telogen (resting phase) was determined microscopically [26].

III. Hair follicle counting: Digital photomicrographs were taken from representative areas of slides at a fixed magnification of $100 \mathrm{x}$. All images were cropped in a fixed area with a width of $1500 \mu \mathrm{m}$ and then counted hair follicles in deep subcutis manually.

IV. Statistical analysis: Statistical analysis of the data was carried out by one way ANOVA in respect of the test and control groups and followed by Dunnett's test. Differences between data were considered highly significant $\mathrm{P}<0.05$. The software used was Graphpad Instat version 3.06 computer software. The data are reported as mean \pm SEM.

\section{Results}

\section{Primary dermal irritation study}

The total scores for skin irritation in terms of erythema and oedema was calculated after 12, 24, 48 and 72 hours according to OECD scoring system. Results revealed that the developed herbal gel formulation did not cause any erythema or oedema on the intact rabbit skin when observed for 72 hours. The Primary Dermal Irritation Index (PDII) of the formulation was zero; therefore according to OECD guidelines the formulation can be classified as non - irritant to the rabbit skin.

\section{Hair growth promoting activity of EEEA and EELN gel formulation in telogenic C57/BL6 mice}

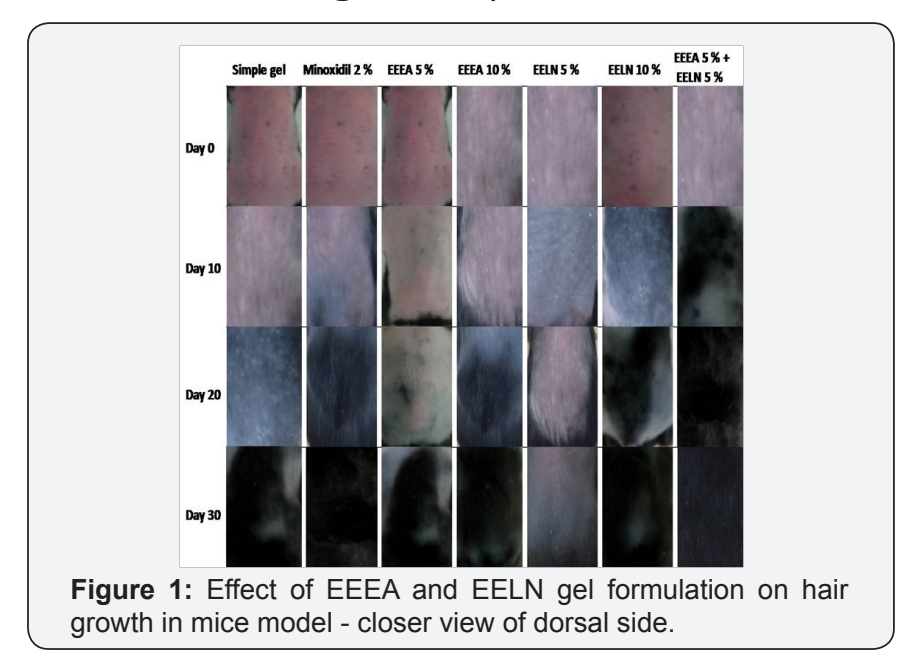

To measure the hair growth promoting activity of EEEA and EELN gel formulation in vivo telogenic C57/BL6 mice were showed one day before topical application of gel formulations. The skin colour of mice in the telogen phase was pink and became dark along with anagen initiation [27]. Since the active growth of hair follicles and black pigmentation occur in C57/ BL6 mice during the anagen phase [28], the hair growth activity of EEEA and EELN gel formulation was evaluated by observing the skin colour. More blacken skin areas were observed in combination of EEEA $5 \%$ and EELN $5 \%$ (HG5) gel formulation and EEEA $10 \%$ (HG2) gel formulation treated groups at 10 days, compared to the control and $2 \%$ minoxidil groups. At 30 days, dorsal skin hairs were fully recovered in HG5 and HG2 gel formulation treated groups whereas only $60 \%$ of the dorsal skin area in the control group was covered with hairs. These results suggest that HG5 (combination of EEEA $5 \%$ and EELN $5 \%$ ) gel formulation induces early telogen to anagen conversion of hair follicles (Figure 1).

\section{Qualitative hair growth study}

Throughout the 30 days study period, all the seven groups of animals were observed closely to determine the hair growth initiation and completion time. This was achieved using a magnifying lens that enabled observation of minute changes in the hair growth pattern. The point at which a tiny prickle of hair growth was observed and it was noted as the initiation time. Combination of EEEA $5 \%$ and EELN 5 \% (HG5) gel formulation treated animals showed significant reduction in hair growth initiation and completion time as compared to control and minoxidil treated animals (Table 4). In control group animals, initiation of hair growth in denuded area was observed in 13.8 days.

Table 4: Effect of EEEA and EELN gel formulation on hair growth initiation and completion time.

\begin{tabular}{|c|c|c|c|}
\hline \multirow{2}{*}{ Treatments } & \multicolumn{2}{|c|}{ Hair growth in days } & \multirow{2}{*}{$\begin{array}{c}\text { Per cent } \\
\text { reduction in } \\
\text { hair growth } \\
\text { completion } \\
\text { time* }\end{array}$} \\
\hline & $\begin{array}{l}\text { Initiation } \\
\text { time }\end{array}$ & $\begin{array}{l}\text { Completion } \\
\text { time }\end{array}$ & \\
\hline $\begin{array}{l}\text { Negative control - } \\
\text { simple gel }\end{array}$ & $13.8 \pm 0.94$ & $42.6 \pm 1.50$ & - \\
\hline $\begin{array}{c}\text { Positive control - } 2 \\
\% \text { minoxidil }\end{array}$ & $7.07 \pm 0.42$ & $33.0 \pm 0.71$ & $22.55^{* * *}$ \\
\hline $5 \%$ EEEA (HG1) & $11.4 \pm 0.66$ & $36.0 \pm 0.45$ & 15.51 \\
\hline 10 \% EEEA (HG2) & $7.01 \pm 0.64$ & $32.4 \pm 0.51$ & $23.96^{* * *}$ \\
\hline 5 \% EELN (HG3) & $12.3 \pm 0.47$ & $39.2 \pm 0.97$ & 8.00 \\
\hline $10 \%$ EELN (HG4) & $10.4 \pm 0.61$ & $35.2 \pm 0.58$ & 17.39 \\
\hline $\begin{array}{l}5 \% \text { EEEA + } 5 \% \\
\text { EELN (HG5) }\end{array}$ & $6.04 \pm 0.71$ & $27.8 \pm 0.66$ & $34.75^{* * *}$ \\
\hline
\end{tabular}

*(Mean of control - Mean of treatment) / Mean of control X 100

${ }^{* * *} \mathrm{P}<0.05$ significant when compared to control (ANOVA followed by Dunnett's test; Values are mean \pm SEM

Hair growth initiation was noted in the first week ( 7.07 days) in mice of minoxidil treated standard group. The formulation HG5 exhibited hair growth initiation on $6^{\text {th }}$ day and HG2 on $7^{\text {th }}$ day whereas with formulation HG1 and HG3 recorded on $11.4^{\text {th }}$ and $12.3^{\text {th }}$ day respectively. Similarly the time taken for complete hair growth on shaved area was promoted with minoxidil treatment as well as gel formulation. Complete hair growth 
with minoxidil and control group as observed in 33 and 42.6 days respectively and in formulation HG3 and HG1 it was 39.2 and 36 days respectively. Likewise hair growth completion was recorded in formulation HG4 and HG2 at 35.2 and 32.4 days respectively. In comparison to control for formulation HG5 the whole denuded area was covered with hair during the $27.8^{\text {th }}$ day. The study findings show that the gel formulation HG5 and HG2 has reduced the hair growth completion time by $34.75 \%$ and $23.96 \%$ as against $22.55 \%$ by positive control minoxidil (Table 4).

\section{Quantitative hair growth study}

A. Hair length determination: The length of the hair began to increase until the end of the treatment course. The formulation HG5 produced a greater effect on the length of hair when compared to other group animals hair being 3.6 $\mathrm{mm}$ at the end of the course ( $30^{\text {th }}$ day), compare to $2.8 \mathrm{~mm}$ in the HG2, $2.4 \mathrm{~mm}$ in minoxidil and HG4 and $1.2 \mathrm{~mm}$ in control groups which received simple gel treatment. HG5 and HG2 gel formulation treated groups produced a greater effect on the length of hair when compared to other groups. This may be due to the premature switching of follicles from the telogen to anagen phase of hair growth cycle. Moreover, in all the groups except the HG2, HG5, HG4 and minoxidil treated groups, the hair looked sparsely. This denotes, the presence of greater number of hair follicles in the anagen phase of the hair growth cycle in $\mathrm{HG}$ 2, HG5, Hg4 and minoxidil treated groups.

A study has been carried out by Adhirajan et al. [2] which proved that the hair follicles periodically transformed from telogen to anagen phase in groups treated by hibiscus flower extract by proliferation of cells in the telogen phase follicles resulting in their conversion to anagen phase [29,30]. A mechanism of conversion of short vellus hairs to long terminal hairs and an enlargement of the follicular size with prolongation of anagen phase by enhancing the rate of cell proliferation has been proven for minoxidil. Also the induction of proliferation of epithelial cells near the base of the hair follicle and vasodilation of scalp blood vessels has been proven [31]. So it was thought that the formulations evaluated in this work could be acting in a similar manner. Average hair length of each group at $10^{\text {th }}$ day, $20^{\text {th }}$ day and $30^{\text {th }}$ day has been given in Table 5 .

Table 5: Effect of EEEA and EELN gel formulation on hair length.

\begin{tabular}{|c|c|c|c|}
\hline \multirow{2}{*}{ Treatments } & \multicolumn{3}{|c|}{ Mean length of hair in mm } \\
\cline { 2 - 4 } & 10th day & 20th day & 30th day \\
\hline Negative control - simple gel & $0.0 \pm 0.0$ & $0.3 \pm 0.0$ & $1.2 \pm 0.20$ \\
\hline $\begin{array}{c}\text { Positive control - } \% \\
\text { minoxidil }\end{array}$ & $0.6 \pm 0.21$ & $1.4 \pm 0.24$ & $2.4 \pm 0.20 * * *$ \\
\hline $5 \%$ EEEA (HG1) & $0.1 \pm 0.0$ & $1.4 \pm 0.24$ & $1.6 \pm 0.24$ \\
\hline $10 \%$ EEEA (HG2) & $0.6 \pm 0.20$ & $1.6 \pm 0.24$ & $2.8 \pm 0.20 * * *$ \\
\hline $5 \%$ EELN (HG3) & $0.0 \pm 0.0$ & $0.6 \pm 0.24$ & $1.2 \pm 0.20$ \\
\hline $10 \%$ EELN (HG4) & $0.2 \pm 0.0$ & $1.8 \pm 0.20$ & $2.4 \pm 0.24 * * *$ \\
\hline $5 \%$ EEEA + 5 \% EELN (HG5) & $0.8 \pm 0.20$ & $2.6 \pm 0.24$ & $3.6 \pm 0.24$ *** \\
\hline
\end{tabular}

${ }^{* * *} \mathrm{P}<0.05$ significant when compared to control (ANOVA followed by Dunnett's test values are mean \pm SEM

\section{B. Histological studies}

i. EEEA and EELN gel formulation on the development of hair follicles: The hair follicle count, skin thickness and color appearance were observed. EEEA (5\%) and EELN (5\%) gel formulation on topical application on rats shows increase in the appearance of colour was only from day 20 to day 30 . Whereas EEEA (10\%) and EELN (10\%) concentration and combination of EEEA (5 \%) and EELN (5\%) gel formulation positive changes observed from day 10. EEEA (5\%) and EELN (5\%) combination gel formulation showed significantly considerable results compared to control. Combination of EEEA (5 \%) and EELN (5 $\%)$ gel formulation and EEEA (10 \%) gel formulation exhibited significant increase in hair regrowth. Increase in the thickness and presence of hair follicles in the subcutis layer were taken as an evidence for transition of follicles from telogen to anagen phase of hair growth. The transition of telogen to anagen phase of hair growth was observed approximately in $88 \%$ animals with $0.2 \mathrm{ml}$ of combination of EEEA (5\%) and EELN (5\%) gel formulation treated groups. The $72 \%$ and $50 \%$ of animals treated with 10 and $5 \%$ of EEEA and EELN respectively also showed transitional from telogen to anagen phase of hair growth (Figure 2).

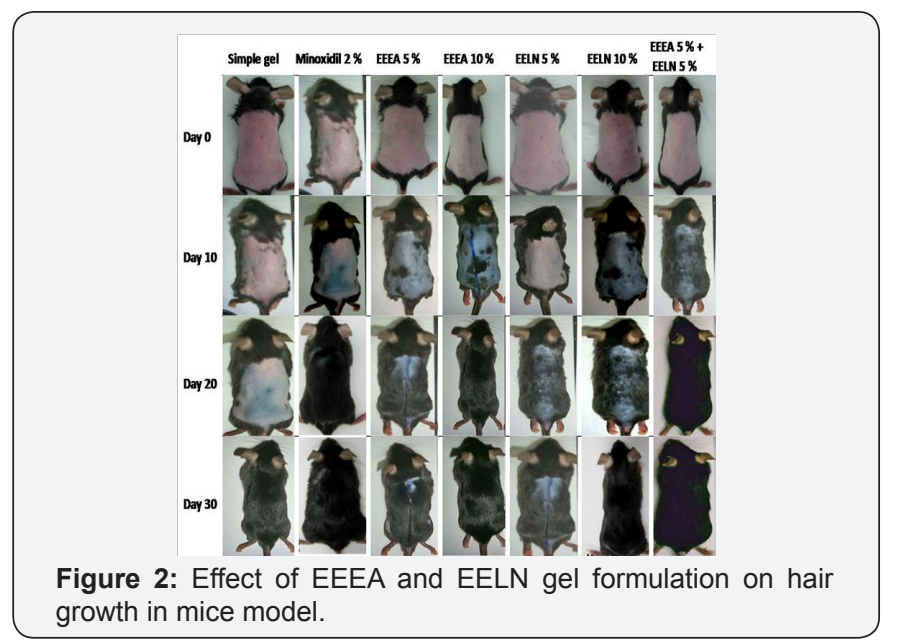

A considerable difference in cyclic phases of hair growth was observed in groups treated with minoxidil, EEEA and EELN gel formulations. An increase in the number and size of hair follicles has been designated as an indicator for the transition of hair growth from the telogen to anagen phase. To examine the progression of hair follicles in the hair cycle, hematoxylin - eosin staining was performed, since an increase in size and number of hair follicles can be observed in the deep subcutis [32]. The photomicrographs obtained indicated that control (simple gel) treated animals had less percentage of anagenic hair follicles (47\%) while the HG5 (73.6\%), HG2 (71\%) and minoxidil (69.4 $\%)$ treated animals showed maximum percentage of anagenic hair follicles and higher follicle density (Figure 3). EELN gel formulations treated groups showed the anagenic follicles 
percentage of 52.3 and 55.1 in formulations HG3 and HG4 respectively and were significant as compared to control but was not as much significant as HG5, HG2 and minoxidil treated groups (Table 6).

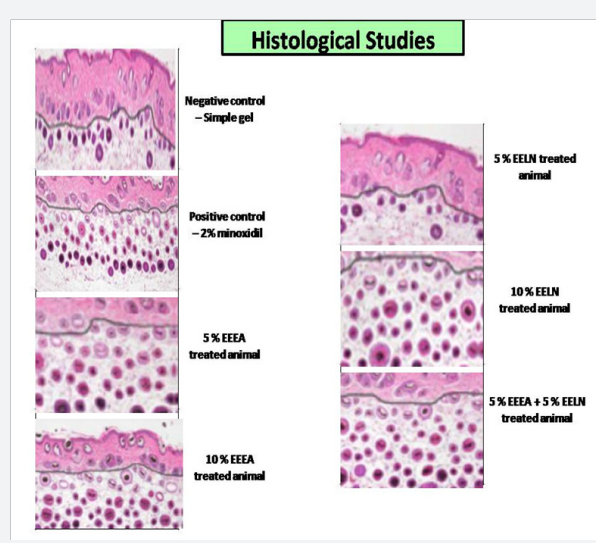

Figure 3: Hair follicle growth in transverse section of the dorsal skin of C57/BL6 mice treated with EEEA and EELN gel formulation.

Table 6: Effect of EEEA and EELN gel formulation on per cent of hair follicles after 30 days.

\begin{tabular}{|c|c|c|c|c|}
\hline Treatments & Telogen & Anagen & $\begin{array}{c}\text { T / A } \\
\text { Ratio }\end{array}$ & $\begin{array}{c}\text { Per cent hair } \\
\text { follicles }>0.5 \\
\text { mm in length }\end{array}$ \\
\hline $\begin{array}{c}\text { Negative } \\
\text { control - } \\
\text { simple gel }\end{array}$ & $48.3 \pm 0.94$ & $47.0 \pm 0.72$ & 1.03 & $28.4 \pm 0.92$ \\
\hline $\begin{array}{c}\text { Positive } \\
\text { control - } \\
\% \text { minoxidil }\end{array}$ & $25.2 \pm 0.17$ & $69.4 \pm 0.77$ & 0.36 & $46.3 \pm 1.03^{* * *}$ \\
\hline $\begin{array}{c}5 \% \text { EEEA } \\
\text { (HG1) }\end{array}$ & $26.7 \pm 0.81$ & $65.1 \pm 0.32$ & 0.41 & $39.6 \pm 0.69$ \\
\hline $\begin{array}{c}10 \% \text { EEEA } \\
\text { (HG2) }\end{array}$ & $23.1 \pm 0.36$ & $71.0 \pm 0.43$ & 0.33 & $45.9 \pm 1.11^{* * *}$ \\
\hline $\begin{array}{c}5 \% \text { EELN } \\
\text { (HG3) }\end{array}$ & $40.4 \pm 0.67$ & $52.3 \pm 0.68$ & 0.77 & $29.4 \pm 0.67$ \\
\hline $\begin{array}{c}10 \% \text { EELN } \\
\text { (HG4) }\end{array}$ & $39.3 \pm 0.32$ & $55.1 \pm 0.91$ & 0.71 & $33.1 \pm 1.10$ \\
\hline $\begin{array}{c}5 \% \text { EEEA + } \\
5 \% \text { EELN } \\
\text { (HG5) }\end{array}$ & $22.6 \pm 0.44$ & $73.6 \pm 0.57$ & 0.31 & $46.9 \pm 0.91^{* * *}$ \\
\hline
\end{tabular}

${ }^{* * *} \mathrm{P}<0.05$ significant when compared to control (ANOVA followed by Dunnett's test values are expressed as per cent of mean \pm SEM

\section{Discussion}

A number of investigations have shown that flavonoids and triterpenoids possess hair growth promoting activity by strengthening the capillary wall of the smaller blood vessels supplying hair follicles, improve blood circulation to nourish the hair follicles and thereby promoting hair growth [33]. Other workers also implicate flavonoids in stimulating telogen to anagen phase, a process involved in hair growth and also cause expressions of some growth factors, such as insulin like growth factor - 1 (IGF - 1), vascular endothelial growth factors (VEGF), keratinocyte growth factors (KGF) and hepatocyte growth factors (HGF) all of which has stimulatory effects on hair growth $[34,35]$. Herbal drugs generally exert their hair growth promotion effects by improving blood flow to scalp either by slight skin irritation or by angiogenesis (improving vasculature through endogenous substances) [36,37]. Gel formulation of EEEA and EELN on topical application reduced the time required for hair growth initiation and completion and was superior to standard (2\% minoxidil solution).

The quality of hair in the gel formulation of EEEA and EELN treated group was coarse and rough whereas the minoxidil treated group resulted in soft and silky hairs. The usage of synthetic drugs, minoxidil and finasteride approved by FDA [38] have abbreviated due to their side effects. After 5 years of minoxidil usage the improvement has been shown to peak for one year with a slow decline in regrowth over subsequent years. These crises lead to the search for natural products from plant origin possessing potential hair growth activity. Our research outcome in accordance with many earlier research findings for hair growth promoting activity of medicinal herbs. Methanolic extract and its water insoluble fraction of green tea showed the presence of phenolic compounds. EGCG (epigallocatechin3-gallate), a major constituent of polyphenols of green tea was reported to be useful in the treatment of androgenetic alopecia by selectively inhibiting $5 \alpha$ reductase activity [39]. It could be considered that the phenols present in the extract are responsible for hair growth promoting activity. Eclipta extracts are a common ingredient in hair oils, shampoos, conditioners and hair dyes.

When Eclipta leaf extracts are mixed with mineral oil and applied to the hair, the hair will become dark and silky. Eclipta hair oil thus removes gray hairs. Eclipta extracts are a source of nutrition for the scalp and prevents hair loss. When the Eclipta hair oil is massaged into the scalp, there is an increase in blood circulation causing the hair roots to become stronger [40]. Eclipta alba L., Hassk contains Ecliptine that is regarded as the primary reason for Eclipta's hair loss arresting properties. Eclipta is composed of a substance called wedelolactone that mimics the action of certain hormones and is responsible for influencing hair-growth. Secondly, Eclipta alba L., Hassk is a natural disinfectant.

It has the ability to neutralize the action of skin allergies and conditions like dermatitis that impair the action of hair follicles, causing increased hair fall. Study of Krishna moorthy et al. [41] clearly revealed that the gel formulation containing extracts of Phyllanthus emblica, Bergamiia koenigii, Lawsonia alba, Indigofera tinctoria and Eclipta prostrate has hair growth promoting effect and it is relatively comparable to minoxidil 2 $\%$ preparation. Considering legacy of usage of these two herbs for various health care practices, the above findings suggests that the combination gel formulation will be safe, effective and 
economical preparation for managing hair fall problem and hair growth promotion.

\section{Conclusion}

In conclusion, the effect of EEEA and EELN gel formulation on the qualitative hair growth and length was found to be more significant as compared to standard and control group treated animals. The quantitative effect of HG5 gel formulation definitely promotes hair growth by inducing hair follicles in the anagen phase. The percentage of anagen induction with EEEA $5 \%+$ EELN 5 \% (HG5) gel formulation and minoxidil were comparable. On the basis of similarities observed between the minoxidil and the HG5 studies, it is expected that EEEA $5 \%+$ EELN 5\% (HG5) gel formulation showed the best hair growth activity compared with minoxidil. In future this gel formulation will be tested on human volunteers for its hair growth activity.

\section{Acknowledgement}

The authors wish to acknowledge DBT, New Delhi and Dr. Ruckmani, Professor and Head, Department of Pharmaceutical Technology, BIT campus, Anna University, Trichy for the support given in regard to analytical instrument facility and animal studies.

\section{References}

1. Arakawa T, Emoto K, Utsunomiya S, Hagiwara Y, Shimizu T (1962) Effect of Swertinogen in hair growth with special reference to its activities on skin function. Tokushima J Exp Med 9: 37-59.

2. Adhirajan N, Ravikumar T, Shanmugasundaram N, Babu M (2003) In vivo and in vitro evaluation of hair growth potential of Hibiscus rosa sinensis Linn. J Ethanopharm 88(2-3): 235-239.

3. Han A, Mirmirani P (2006) Clinical approach to the patient with alopecia. Semin Cutan Med Surg 25(1): 11-23.

4. Paus R, Cotsarelis G (1999) The biology of hair follicles. N Engl J Med 341(7): 491-497.

5. Whiting DA (2001) Possible mechanisms of miniaturization during androgenetic alopecia or pattern hair loss. J Am Acad Dermatol 45(3): S81-S86.

6. Yoo HG, Kim JS, Lee SR, Pyo HK, Moon HI, et al. (2006) Perifollicular fibrosis pathogenetic role in Androgenetic alopecia. Biol Pharm Bull 29(6): 1246-1250.

7. Cotsarelis G, Millar SE (2001) Towards a molecular understanding of hair loss and its treatment. Trends Mol Med 7(7): 293-301.

8. Bagatell C, Bremner WJ (1996) Androgens in men - uses and abuses. New Engl J Med 334(11): 707-714.

9. Bhaumik S, Jyothi MD, Khar A (2002) Differential modulation of nitric oxide by curcumin in host macrophages and NK cells. FEBS Lett 483(1): 78-82.

10. Olsen EA (1993) Androgenetic alopecia. In: EA Olsen (Eds.), Disorders of Hair Growth: Diagnosis and Treatment, McGraw Hill Inc, USA, pp. 257-87.

11. Takahashi T, Kamiya T, Yokoo Y (1998) Proanthocyanidins from grape seeds promote proliferation of mouse hair follicle cells in vitro and convert hair cycle in vivo. Acta Derm Venereol 78(6): 428-432.

12. Vaishali Rathi, Jagdish Chandra Rathi, S Tamizharasi, Anupam Kumar
Pathak (2008) Plants used for hair growth promotion: A review. Pharmacognosy Review 2(3): 185-187.

13. Joshi SG (2004) Medicinal Plants. Oxford and IBH Publishing Co. Pvt. Ltd, India, p. 81.

14. Daniel M (2006) Medicinal Plants, Chemistry and properties. Oxford and IBH Publishing Co. Pvt. Ltd, India, pp. 148-149.

15. Khare CP (2004) Encyclopedia of Indian Medicinal Plants. Springerverlag Berlin Heidelberg, USA, pp. 197-198.

16. P Srinivasa Reddy, Kaiser Jamil, P Madhusudhan, G Anjani, B Das (2001) Antibacterial activity of isolates from Piper longum and Taxus baccata. Pharmaceutical Biology 39(3): 236-238.

17. Joshi BC (1970) Chemical examination of Lippia nodiflora. Vijnana Parishad Anusandhan Patrika 11(4): 214-219.

18. H Khalil, H Ismail, A Taye, M Kamel (2007) Gastroprotective effect of Lippia nodiflora L. extracts in ethanol induced gastric lesions. Pharmacognosy Magazine 3(12): 258-261.

19. Ahmed F, Selim MS, Das AK, Choudhuri MS (2004) Anti-inflammatory and antineoceptive activities methanolic extract of Lippia nodiflora Linn. Pharmazie 59(4): 329-330.

20. Durairaj A, Vaiyapuri TS, Kanti MU, Malaya G (2008) Protective activity and antioxidant potential of Lippia nodiflora extract in paracetamol induced hepatotoxicity in rats. Iranian Journal of Pharmacology \& Therapeutics 7(1): 83-89.

21. Sangita Shukla, Rashmika Patel Rajiv Kukkar (2009) Study of phytochemical and diuretic potential of methanol and aqueous extracts of aerial parts of Phyla nodiflora Linn. International Journal of Pharmacy and Pharmaceutical Sciences 1(1): 85-91.

22. Patni P, Varghese D, Balekar N (2006) Formulation and evaluation of herbal hair oil for alopecia management. Planta Indica 2: 27-30.

23. Mithal BM, Shah RN (2000) A Hand Book of Cosmetics. ( $1^{\text {st }}$ edn), Vallabh Prakashan. India.

24. Adhirajan N Dixit VK Gowri C (1999) Development and evaluation of herbal formulation for hair growth. Indian Drugs 38: 559-563.

25. Roy RK, Thakur M, Dixit VK (2006) Effect of Cuscuta reflexa Roxb. on hair growth activity of albino rats. Indian Drugs 43: 951-956.

26. Uno H (1991) Quantitative models for the study of hair growth in vivo. In: KS Stenn (Eds.), Molecular and Structural Biology of Hairs, Volume 642, New York Academy of Science, USA, pp. 107-124.

27. Paus R, Foitzik K (2004) In search of the "hair cycle clock": A guided tour. Differentiation 72(9-10): 489-511.

28. Peters EM, Botchkarev VA, Botchkareva NV, Tobin DJ, Paus R (2002) Hair cycle associated remodeling of the peptidergic innervations of murine skin and hair growth modulation by neuropeptides. J Invest Dermatol 116(2): 236-245.

29. Ralf Paus (2006) Therapeutic strategies for treating hair loss. Drug discovery today: Therapeutic Strategies 3(1): 101-110.

30. Philpot MP, Green MR, Kealey T (1992) Rat hair follicle growth in vitro. $\mathrm{Br} J$ of Dermatol 127(6): 600-607.

31. Uno H, Kurata S (1993) Chemical agents and peptides affect hair growth. J Invest Dermatol 101(1): 143S-147S.

32. Datta K, Singh AT, Mukherjee A, Bhat B, Ramesh B, et al. (2009) Eclipta alba extract with potential for hair growth promoting activity. J Ethnopharmacol 124(3): 450-456.

33. Kobayashi N, Suzuki R, Koide C, Suzuki T, Matsuda H, et al. (1993) Effect of leaves of Ginkgo biloba on hair growth in C $3 \mathrm{H}$ strain mice. 
Yakugaku Zasshi 113(10): 718-724.

34. Roh SS, Kim CD, Lee MH, Hwang SL, Rang MJ, et al. (2002) The hair growth promoting effect of Sophora flavescens extract and its molecular regulation. J Dermatol Sci 30(1): 43-49.

35. Rho SS, Park SJ, Hwang SL, Lee MH, Kim CD, et al. (2005) The hair growth promoting effect of Asiasari radix extract and its molecular regulation. J Dermatol Sci 38(2): 89-97.

36. Mona Semalty, Ajay Semalty, Geeta Pant Joshi, MSM Rawat (2008) Herbal hair growth promotion strategies for alopecia. Indian Drugs 45(9): 689-700.

37. Mona Semalty (2009) Correlation in hair growth and antioxidant activity of some Himalayan medicinal plants. Journal of Global Pharma Technology 3(12): 1-6.
38. James F Libecco, Wilma F Bergfeld (2004) Finasteride in the treatment of alopecia. Expert Opin Pharmacother 5(4): 933-940.

39. Kwon OS, Han JH, Yoo HG, Chung JH, Cho KH, et al. (2006) Human hair growth enhancement in vitro by green tea epigallocatechin-3-gallate (EGCG). Phytomedicine 14(7-8): 551-555.

40. Aclepsa. Com, Online Health superstore (2007) “Eclipta Raj Hair Oil”.

41. JR Krishnamoorthy, R Sumithira, S Gokulshankar, Ranjith, S Ranganathan, et al. (2010) Hair growth modulating effect of a novel herbal formulation-A rediscovery of traditional knowledge. J Appl Cosmetol 28: 147-151. 